\title{
The linguistic disadvantage of scholars who write in English as an additional language: Myth or reality
}

\author{
John Flowerdew \\ University of Lancaster and Birkbeck College, University of London, UK \\ Email: johnflowerdew888@gmail.com
}

(Received 2 December 2018)

Academics are coming under increasing pressure to publish internationally. Given the global dominance of English, this very likely means publishing in English-medium journals and with publishers which publish in English. This raises the important question of the possible disadvantage of those scholars whose first language is not English and who therefore have the additional burden of having to develop adequate proficiency in an additional language, English. As a student of modern languages to university level and of other languages to rather lower levels of proficiency and as a teacher of English for academic purposes (EAP) and of English for research and publication purposes (ERPP), since I became aware of this issue, I have always believed this extra burden on the English as an additional language (EAL) academic writer to be a self-evident truth. Ken Hyland, however, in a recent book (Hyland, 2015) and an article titled 'Academic publishing and the myth of linguistic injustice' (Hyland, 2016a), has taken it upon himself to argue that such an assumption is ill-founded. Hyland argues that native-speakers (NSs) of English encounter the same difficulties as non-native speakers (NNSs) when it comes to academic writing, that 'academic English is no one's first language', and that it requires 'deliberate learning' by both NSs and NSs (p. 57). Native and non-native writers, Hyland implies, are on a level playing field when it comes to writing for publication, both groups having to jump the same hurdles.

I first encountered this position of Hyland in 2008, when, along with Ken, Maurizio Gotti, and John Swales, I was privileged to be invited as a plenary speaker at a conference in Spain organized by the University of Zaragoza. ${ }^{1}$ At the end of the conference, there was a question and answer session, with members of the audience putting questions to a panel made up of the plenary speakers. One of the questioners asked if it was more difficult or not for an EAL writer when it came to writing for publication. Both Swales and Hyland, I recall, put forward the argument as presented above, that both NSs and NNSs are presented with the same challenges of having to acquire the appropriate academic register. Rather surprised at these responses by such eminent scholars and experienced editors, when it came to my turn, I turned the question around and asked the members of the audience to raise their hand if they thought it was more difficult. Unsurprisingly (to me, at any rate), nearly all of the members of the audience, the great majority of whom were Spanish, raised their hand. This phenomenon of EAL writers having a different view on this issue to his own is taken up by Hyland in the publications referred to above and he argues that, although there is quite a literature on this issue, it is misguided and a 'myth' that EAL writers are at a disadvantage, as indicated in the title of his article. ${ }^{2}$ In this invited position piece, I would like to take up this issue and present my own perspective.

\section{Hyland's arguments and my responses}

So what is Hyland's argument in more detail? In this piece, I will focus on the 2016a article. Hyland argues that there are in fact two myths regarding the 'purported' disadvantage of the EAL writer. These two myths are first, that native writers have an advantage because they acquire the language (c) Cambridge University Press 2019 
naturalistically, while EAL writers need to spend time, effort and money in formally learning it; and second, that editors and referees are prejudiced against EAL writers because they use non-standard English. Hyland argues that although poor linguistic skills are frequently associated with these factors, there are more significant disadvantages such as 'physical, scholarly, and financial isolation' which may be putting the EAL scholar at a disadvantage than that of language (p. 59). On this basis he argues that 'framing publication problems as a crude native vs non-native polarization functions to demoralize EAL writers and ignores the very real writing problems experienced by many L1 English scholars (p. 59)'. While I would agree with Hyland that the other factors he mentions as being an impediment to EAL writers are important (see also Swales, 2004) (and that these other factors also apply to some first language (L1) writers), I think it is a mistake to dismiss the language issue so categorically. Neither do I agree with Hyland on the issue of editor and reviewer bias, although I do not take a strong position here.

In the following, I will explain why I hold these views. I should also mention here that, in preparing this article, I have come across two other critiques of Hyland's paper, the first a blog-post by Subtirelu (2016) and the second an article published in the same journal as Hyland by Politzer-Ahles, Holliday, Girolamod, Spychalskae, and Harper Berkson (2016). What I have to say in the following will partially overlap with some of the points made in these pieces and I will indicate where this is the case. I should also mention that there is also a reply to Politzer-Ahles et al. (2016) by Hyland (2016b).

\section{Hyland argument 1: NSs do not have an advantage over EAL writers}

Let us take the EAL/L1 writer dichotomy first (and this will be the major argument that I want to make in this article). Hyland argues that:

... assertions that EAL authors have greater difficulties in writing than their Native English counterparts are largely speculative - while self-reports tell us it is, we just don't know if it is the case or not. (p. 61)

Now, I may be missing something, but I cannot understand why Hyland is using the term 'speculative' here and why he claims that 'we just don't know' if EAL writers have greater difficulties. Indeed, prior to this statement Hyland had presented a lot of evidence from a considerable number of studies that indicate that EAL academic writers do report that they find it more difficult to write in English than their L1, but he dismissed it, saying that there are other variables such as L1, discipline, and publishing experience which 'cross-cut' this evidence (p. 60). But, surely, these other variables only affect relative levels of difficulty, not absolute values. Writing in a second language (L2) must be either more difficult, less difficult, or (unlikely) the same level of difficulty. The other variables Hyland refers to will not change these absolute values. If we compare an EAL writer who has an L1 which is typologically relatively close to English, say French or Spanish, with an EAL writer from an L1 background which is typologically more distant, say Chinese or Vietnamese, the latter writer may find writing in English more of a challenge than the former, but writing in English, an additional language, will still be more difficult than writing in their L1 for both types of EAL writer. If we take publishing experience, whether or not an EAL writer has a lot of experience in writing and publishing in English, other things being equal, they would still have found it easier if they had gone through this whole apprenticeship process in their L1 rather than an additional language. In support of his claim, Hyland even also argues (p. 61) that many EAL authors are successful in publishing. But the fact that they publish papers does not have any bearing on whether or not it is more difficult for their authors to write them or get them published. It is the case that some EAL writers only write in English and not their mother tongue, but even here, if they did not have to write in English and could publish in their L1, then this would be easier for them, assuming that their mother tongue possessed the genre of the research article (which, due to the hegemony of English, is very often unfortunately not the case).

Presumably, Hyland means that empirical studies have not been conducted to test these assertions regarding greater difficulty for EAL writers. But surely, even if it were possible to create two equivalent 
groups of EAL and L1 writers and ask them to write an academic article, which it is not - because there would be just too many variables to control - we do not need to conduct any studies to test this assumption. Anyone who has spent any time learning an L2 will realize immediately that it will be more difficult to write in the L2 than the L1, even after many years of study and practice. Even senior professors with many years of experience will tell you that, as they did in the survey I conducted many years ago now (Flowerdew, 1999), which is cited by Hyland. Hyland implies that we cannot believe self-reports. I see no particular reason to doubt them in this case.

Hyland claims that 'writing for publication is a specialized competence which both Native and Non-Native English speakers must acquire' (p. 61). This 'FACT' (Hyland's term, my emphasis) is obscured by two assumptions, Hyland claims: the native/non-native divide, on the one hand, and the primacy of language, on the other. Hyland borrows arguments from Ferguson (2007) to counter these assumptions. With regard to the first of these claimed assumptions, the native/non-native divide, Hyland argues that the terminology is problematic; the term 'non-native' can be applied to varying levels of proficiency. I alluded to this issue in my introduction and agree that the NNS/NS dichotomy is a relative one. This does not mean that it has no relevance here though ${ }^{3}$ (although I agree that in other contexts the 'non-native' label may carry features of stigma). In addition, for Hyland:

[A]lthough the idea of Native-Speaker might imply the advantages gained by having internalized the language through 'natural acquisition,' rather than through deliberate learning, academic English is no one's first language. In fact, 'Nativespeakerhood' refers more accurately to the acquisition of syntactic and phonological knowledge as a result of early childhood socialization and not competence in writing, which requires prolonged formal education. We don't learn to write in the same way that we learn to speak, but through years of schooling. (p. 61)

There are problematic issues in the above argument. First, NSs are likely to have received the 'lengthy formal education' in English Hyland refers to, whereas EAL writers will have spent most time learning to write at school in their L1; writing in the L2 will likely have received much less attention on the part of EAL writers. Second, and more importantly, in my view, Hyland is too dismissive of what he refers to as the acquisition of 'syntactic and phonological knowledge'. Leaving aside phonology here, given that we are concerned with writing, Hyland seems to be suggesting that there is 'syntax', on the one hand, and academic writing, on the other; they are two totally separate sets of skills which do not interact. 'Syntax' is not relevant here, he seems to be saying, because academic writing requires different skills, which are the same whether we are talking about EAL or L1 academic writers. But, in my view, this is to underestimate what he refers to as 'syntax' here.

As Hyland concedes, syntax is naturally acquired by NSs. So, right away, there is an additional burden here for the EAL writer, who normally would have to devote many hours of schooling to consciously learn this system. But, in addition, reducing the language to syntax is to massively underestimate the domain of the language competence that is naturally acquired by mother tongue users. Syntax refers to language form, but we also need to consider meaning and use. There are subtle features of meaning and use attaching to syntactic forms which are naturally acquired by the L1 writer in the home and at school, but which take many years for the EAL learner to develop. Hyland is well known for his studies on the subtleties of meaning and use in disciplinary contexts, his work on hedging, on metadiscourse, on stance, and on identity, being rightly lauded as very original and important work. So, it is surprising that he should neglect these important features of language competence. While these various functional categories vary according to specific disciplines, as Hyland, among many others, has demonstrated, it is likely that NSs will have a broad (non-discipline-specific) command of these language functions before embarking on disciplinary writing. It is not a case of these features operating only in specific disciplines. While there may be discipline-specificity, there will also be some sort of broad general competence. And, of course, the development of such a general competence is likely to be more challenging for the EAL writer than the native writer, because the native writer will have likely developed such general competence in the home, reading media materials, and 
during schooling. Another way to consider this issue is by means of the concept of register (which Hyland also uses, see below). ${ }^{4}$ A register is a particular configuration of linguistic forms - lexis, grammar, rhetorical patterns - which varies according to situation (Halliday, 1989, p. 44). To deploy a register, with some notable register-specific exceptions (mostly lexis), you employ the same tools as in other situations (you draw on your repertoire), but you configure this repertoire according to the accepted semantic and pragmatic conventions of the particular situation (for our purposes here, writing a research article).

Let me provide some examples to illustrate what I mean here. First, an important function in writing research articles in science is 'identifying the appropriate level of claim' (Myers, 1990). There are likely to be particular ways in which this is done in a given discipline, but in general terms writers will need to have a good command of the modality system in English. L1 writers will have acquired what I would refer to as a general command of this system as they grew up through everyday life and schooling. They would later have to develop a command of the particular ways modality is used in their target discipline and genre of the research article, but they would start out with a general competence in the use of modality. EAL writers, on the other hand, would need to develop such a competence formally, when they learn the language.

As a second example, below are some sentence fragments analysed by Williams (1999) in his study of results sections of medical research articles:

1. The results of this analysis are given in Table $3 \ldots$

2. ... since by design we used a lower dose of the nephrotoxin ...

3. A significant correlation was found between PLI and nodal status in the TNM classification ...

4. Proteinuria in Adriamycin-treated animals evolved from a value at two weeks of ...

The extracts show that there is a range of verb forms (in bold) employed in the results section of the research article: (1) simple present tense passive; (2) simple past tense active; (3) simple past tense passive ; (4) simple past tense active (intransitive). Now, each of these different verb forms is playing a particular functional role in these extracts: referring the reader to a table in (1), describing a procedure in (2), reporting a specific result in (3), and describing a process in (4). This is the discipline-specific aspect of these verb forms, which, I am sure Hyland would agree, both the L1 and the EAL writer will have to learn how to use. However, a NS-like command of tense, aspect, voice, and transitivity before coming to these discipline-specific uses is likely to put the L1 writer at an advantage over the EAL writer. Having used these forms in many other contexts at home and in school, the L1 writer will be able to intuitively make judgments as to the appropriacy of these various patterns. The EAL writer, on the other hand, will be less confident, having had to learn them in a formal setting and probably not having had much opportunity to apply them in real-world uses. In short, the L1 writer will be more able to competently manipulate these patterns than the EAL writer, who will likely be less confident in making judgments about the accuracy of their work (and consequently more likely to have to seek some sort of assistance).

In addition to syntax and phonology, there is a range of other linguistic features that are overlooked by Hyland here and which are likely to prove to be a greater challenge for EAL writers than L1 writers. Rather confusingly, later in his article (p. 66), Hyland does include lexis and discourse, in addition to 'syntax', as difficulties for the EAL writer, but he downplays their importance. Discussing an article by Englander (2006), he states:

It is register rather than the language that is at issue. This is not to say that difficulties with English SYNTAX, LEXIS, or DISCOURSE do not greatly complicate the task of non-Anglophone academics, but it calls into question a coarse Native vs. Non-Native dichotomy (emphasis added) (Hyland, p. 66).

With regard to lexis, the L1 writer is likely to have, other things being equal, a more extensive vocabulary than the EAL writer. Again, while there will be a discipline-specific terminology that 
has to be acquired by both EAL and Native writers, there is also, importantly, a considerable academic vocabulary that is not specific to any particular discipline. I am thinking of the sort of vocabulary included in Coxhead's academic word list www.victoria.ac.nz/lals/resources/academicwordlist. This list does not include what Coxhead refers to as basic vocabulary, but consists of the most frequent academic words occurring across 28 different subject areas from four disciplinary domains. This is not disciplinary vocabulary, therefore, but general academic vocabulary. The following are some of the words in the highest frequency section of Coxhead's list.

area; benefit; define, environment, factor; issue; research; vary

And the following are from the among the less frequent section:

adjacent; forthcoming; integrity; levy; notwithstanding; panel; persistent; so-called

This vocabulary has also been referred to in the English for special purposes (ESP) literature as semitechnical (Cowan, 1974; Robinson, 1980; Trimble, 1985) or sub-technical (Johns \& Dudley-Evans, 1980) vocabulary. Although such vocabulary items occur frequently across academic disciplines (with subtle shades of meaning according to specific disciplinary contexts), they also belong to the vocabulary of the general educated person. The EAL user would have to learn these items, while they are likely be part of the vocabulary of any secondary school graduate whose L1 is English. Indeed, they might be found in any broadsheet newspaper. Furthermore, many of the discipline-specific uses of these items are metaphorical extensions of their core meaning. Take, for example, the meaning of BENEFIT(s) in the context of social security payments, or of INTEGRITY (of a system) in the context of information technology. Knowledge of the core meaning, which the L1 writer will naturally acquire as part of their upbringing and which the EAL writer will have to consciously learn, will likely facilitate comprehension of the discipline-specific meaning.

In addition to vocabulary, there are the important related areas of collocation, colligation and lexical bundles (the latter another feature to have been studied by Hyland incidentally). High levels of competencies in these features are the domain of only the very advanced EAL user. More average EAL writers may struggle with such features of the language. This is why EAL writing often contains non-standard collocations which do not tend to occur in L1 writing. L1 writers can be confident of their appropriacy and accuracy when writing a collocation or colligation, while EAL writers are more likely to need to check with a dictionary or corpus, if available (or ask an NS, also if available) (see articles by Pérez-Llantada (2015) and Li and Schmid (2009) on EAL academic writers' difficulties with phraseology). Because of such difficulties, some EAL writers resort to copy-and-paste, borrowing chunks of language from published papers and incorporating them into their own writing. Yongyan $\mathrm{Li}$ and I discovered such a practice among the doctoral science students writing for publication that we studied in Mainland China (Flowerdew \& Li, 2007). While such a practice may be perfectly permissible if used strategically and limited to relatively short chunks of a few words, some writers, as Li and I found, use the practice for much larger chunks and risk accusations of plagiarism.

Turning now to connected discourse, as with the other linguistic features discussed above, the EAL writer will also be at a disadvantage, the L1 writer having developed a command of these features as part of their schooling and the EAL writer having focused on such features at school mainly in the L1. I am thinking here of the cohesive features highlighted by Halliday and Hasan (1976) of reference, substitution, ellipsis and lexical cohesion and the discourse features of theme/rheme and given/new (Halliday \& Matthiessen, 2004). The following is a reviewer comment cited by Moreno (2012, p. 15) on a submission from Spain, highlighting an issue with anaphoric reference:

It would be useful to have the article carefully read by a Native English speaker to check for consistency in register, APPROPRIATE USE OF ANAPHORIC REFERENCE and transfer from Spanish. (emphasis added) 
This latter comment, with the phrase 'transfer from Spanish', also highlights the issue of possible transfer from the writer's L1. This is an important further consideration in the argument I am presenting here. Features of an EAL writer's L1 are likely to transfer into their English. This occurs, of course, at the level of grammar and connected discourse, but it is also an issue at the rhetorical/functional level - how an EAL writer's cultural style may contrast with that of the standard Anglophone rhetorical style. The EAL writer seeking to publish in Anglophone journals is likely to have to conform to Anglophone styles. What may be an appropriate cultural style in an EAL writer's L1 may be problematic in English (Moreno, 2012). The scientific method is usually considered to be universal. However, as pointed out by Pérez-Llantada (2012), the way EAL writers perform certain rhetorical functions in their writing may vary. Example functions cited by Pérez-Llantada (2012) in her study of Spanish writers are 'the construction of persuasive arguments, the degree of critical stance, the construction of an authorial persona through personal pronouns, or the use of implicit and explicit modes of criticism' (2012, p. 15); the performance of all such rhetorical functions may vary across cultures. Such variation is particularly prominent in the humanities and social sciences, where the scientific method is not as universal as in the natural sciences. In an early analysis of the introductions of research articles in English and Polish in the field of language studies, for example, Duszak (1994) identified variation between the amount of information revealed and the amount of face work across the two languages. On the basis of such differences, Duszak (1994) argued that 'there exist potential areas of (in)compatibility between the two writing styles' (abstract).

Finally, before concluding this section, it is worth pointing out that a further increased burden on the EAL writer lies in the fact that they may need to write and publish in both English and their L1; they may need to cultivate two academic identities rather than just one. Casanave (1998) has shown how Japanese scholars, educated at the graduate level in the United States, struggled with the burden of having to juggle two sets of values and expectations. Similarly, Ling Shi (2003) has written about how Chinese scholars educated in the West had to deal with their biliterate/bicultural intellectual identity and their writing practices in both English and Chinese. On a related issue, both Hewings, Lillis and Vladimirou (2010) and Breeze (2015) have shown that EAL writers may be reluctant to cite publications which are not in English, even if they are written by colleagues in the same department. This phenomenon again highlights not only the existence of two academic identities, but also the (perceived) need to keep them apart.

To conclude this section, I have perhaps laboured the point that I want to make. However, as I have emphasized, it is important not to downplay the linguistic challenge facing EAL writers in the way that Hyland does. Other factors are of course also important, as Hyland argues, but I am not in agreement with him when he claims that linguistic difficulties are a myth and that the challenges facing EAL writers are essentially the same as those for L1 writers. This is definitely not the case, as I hope I have demonstrated.

\section{Hyland argument 2: editors and reviewers are not biased against EAL writers because they use non-standard English}

Let us turn now to the second of Hyland's 'myths' with regard to the publication issue, i.e. that there is bias on the part of editors and referees against non-standard English. Personally, I am not in a position to know to what extent there may be bias or not, because I do not have enough evidence for such a situation either way. I would say on this issue, however, that it is a fact that those journals which require EAL writers to have their work checked by an NS of English are imposing an extra burden on EAL writers which they do not apply to L1 writers. So, to this extent, bias is built into the system. Fortunately, there are signs that such a blinkered view of academic English is eroding, not least because (as Hyland points out) there are now relatively fewer NS editors and reviewers of journals and more non-native English writers participating in the field. Ironically, some of the journals in the field of applied linguistics, however, perpetuate this requirement, including Journal of Second Language Writing, the journal in which Hyland's article was published, and this journal, Language Teaching. 
One of the arguments that Hyland uses to dismiss the claim that there is bias is that EAL writers are successfully getting published. But just because EAL writers are (increasingly) getting published does not mean that they are not encountering greater difficulties than L1 writers in the process or that EAL writers are not being rejected because of their non-standard English. We just do not know. Politzer-Ahles et al. (2016, p. 5) have made this argument as follows:

The fact that many papers do get published does not invalidate concerns that these papers may face disproportionate difficulty in getting published, may tend to be published in lower-impact journals, or may be published (or cited) in disproportionate amounts relative to the overall number of Non-Native English-speaking scholars.

Certainly, the criteria for 'desk' rejection (i.e. rejecting a manuscript without sending it out for review) of the journal Carbon, a peer reviewed journal published by Elsevier, indicate that language can be a factor here. In an internet posting, 'Eight reasons I rejected your article': www.elsevier.com/ connect/8-reasons-i-rejected-your-article, the editor of this journal provides various sub-points for each of the eight reasons. Under the first reason, 'It fails the technical screening', one of the sub-points is 'The English is not sufficient for the peer review process'.

Hyland cites a number of studies on written reviews suggesting that reviewers and editors are sympathetic to non-standard English and that they consider content to be more important than language. While I agree with the second part of this statement, I am not so sure about the first part. Certainly, some editors are sympathetic to non-standard English, but we need to bear in mind a number of factors here. First, the studies referred to by Hyland were conducted with regard to the journals Applied Linguistics and Language Teaching, whose editorial boards and reviewers are (hopefully) likely to be more enlightened with regard to non-standard English. Second, EAL writers submitting to such journals are language specialists who are likely to have a higher standard of English than EAL writers from other disciplines. Third, to cite Politzer-Ahles et al. (2016, p. 5) again, various studies have demonstrated that individuals are unable to acknowledge if they are biased with regard to a particular issue or not; they are 'notoriously poor at identifying their own unconscious biases, and even the most well-meaning of people often harbour implicit biases that can sometimes be revealed only with sensitive tasks'. Fourth, a point made by Subtirelu (2016), the fact that reviewers do not comment negatively on language does not preclude the possibility that their judgment may be negatively coloured by the quality of the writing; I know that in my case, as a reviewer, I would likely intuitively be more positively disposed towards a well-written manuscript than a poorly written one, whoever the writer might be.

In their study of peer review of articles in education and psychology in four 'periphery' European countries, Lillis and Curry (2015) found that, out of 95 'text histories' they collected, in 58 (68\%) of them, at least one of the evaluators (the editor and/or one or more of the reviewers) 'foreground English or language as a significant problem with the article.' (p. 134). On this basis, Lillis and Curry concluded that '[f]indings from the quantitative analysis therefore indicate that English and language are indeed construed as a problematic issue.' (p. 134). The following are some of the comments reported by Lillis and Curry (2015) from their collection of text histories:

- It needs a language edit. By and large, the paper is scholarly, if a little laboured, which may be the result of second language difficulties, but not entirely.

- There are quite a number of instances in the text where it is clear that English is not the authors' first language. They cannot be blamed for that, of course, but it does make the text difficult to understand at times.

- Unfortunately, the writing is still [after revision] unclear and difficult to follow in many sections of the manuscript. I truly sympathize with you because I suspect that English may be a second language. However, the lack of clarity and jumps in logic make it hard for the reader to 
understand the basic message. It is crucially important that the whole manuscript is proofread and edited by a Native English speaker to make sure that all paragraphs convey the authors' intended meaning accurately.

- The paper needs to be corrected for English. It has many errors and uses words not appropriate in English. A Native-Speaker should correct the manuscript.

- You may want to give your paper to a Native English language speaker to language edit it so that you will be sure that the meaning of what you want to say passes; surely I strongly recommend that you do so. I say this since I have traced some English language expression errors (syntactical or other).

- There are numerous small 'oddities' in expression that are too numerous for me to fix them - the authors may ask an English speaker to go through the manuscript to fix these.

These data clearly demonstrate negative evaluation of language. As a caveat here, I should point out that quality of language does not necessarily refer to English - the 'jumps in logic' referred to in the third comment above, for example, are not an issue with English, but with argumentation - but it is significant that all of these comments refer specifically to English or a 'second language'. While we cannot extrapolate from these comments that there is negative bias (indeed, reviewers may well be trying to assist authors with these comments), they do show that language is certainly a factor in decision making. Furthermore, given that it is unlikely that such comments would be made on submissions from L1 writers, it follows that EAL writers are singled out as a particular group (even though they may be in the majority and the editorial comments and reviews may well have been written by EAL writers themselves). It is also interesting to note how the last four comments suggest a 'Native-Speaker' of English should be sought out to help with the editing. It is not always the case, however, that a 'Native-Speaker' is available or can be afforded in all EAL settings, for example the location in Mainland China where the data for my publication with Yongyan Li were collected (Flowerdew \& Li, 2007).

\section{Hyland's reasons for wanting to debunk the two purported myths and my responses}

Hyland presents two reasons as to why he wants to debunk his two purported myths, which, again, I would like to take issue with. ${ }^{5}$ They are as follows (p. 67):

1. By focusing on language shortcomings it [the disadvantage position] perpetuates a myth of L2 deficit, which discourages EAL authors and tells them to look for prejudice rather than revision.

2. It marginalizes the challenges faced by native English-speaking authors by depicting Kachru's Inner Circle as a kind of safe house where academic publication can be taken for granted.

The first of these two arguments was previously put forward by Casanave (2008) in response to an article I wrote (Flowerdew, 2008) in which I speculated on how Goffman's writings on stigma might be considered in relation to the burden of the EAL writer. This is a Panglossian approach, however, according to which everything is for the best; there is no problem, so we do not need to address it. Sweeping the issue under the carpet in this way, however, strikes me as morally questionable. Editors and reviewers will not face up to the reality of linguistic disadvantage and facilitate the efforts of EAL writers if their difficulties are ignored. In this regard, it is interesting that in recent years, in recognition of the difficulties of EAL writers, leading publishers (e.g. Elsevier) have started to provide editing services for prospective EAL contributors. This, of course, benefits the journal editors and reviewers as much as it does the contributors; it makes their job easier in terms of more intelligible submissions and more easily edited final manuscripts. Furthermore, if EAL writers recognize the challenges, they are more likely to address them and seek ways to improve their writing competencies. Similarly, if the difficulties of EAL writers are well known, university administrators are more likely 
to provide dedicated ERPP courses for their EAL academic staff, courses which in many universities are lacking. All of these efforts ultimately, of course, contribute to the creation of knowledge and human development generally.

As for the second of Hyland's arguments, marginalizing the difficulties of novice L1 writers, I would be the first to agree that L1 writers have to struggle with their writing. I know this through personal experience and reading draft manuscripts of L1 writers. The fact that L1 writers have to struggle to get published does not mean that EAL writers, other things being equal, do not need to struggle more, however. It is true that most ERPP research and practical interventions focus on EAL writers, but this probably reflects their greater need, on the one hand, and the fact perhaps also that they have a ready constituency of applied linguists and language teachers to support them, which L1 writers do not.

Habibie (2015) has invoked the notion of the 'Lucky Anglophone Fellow' syndrome in this context (p. 65), according to which it is taken for granted that L1 writers will be able to write and achieve publication and as a result are left to their own devices without any special attention or support. While I agree that there is some truth in this argument, I would not want this to detract from the needs of EAL writers. Indeed, there are signs that ERPP research is starting to focus more on L1 academics (e.g. Habibie, 2015; Paltridge, 2016; Paltridge \& Starfield, 2016; Habibie \& Hyland, 2018), which I welcome.

\section{Conclusion}

How to conclude? In my view, there is a certain set of challenges in writing for publication which are shared by EAL and L1 writers, but EAL writers have an additional set of linguistic challenges, which do not apply (to such an extent) to L1 writers. These challenges may or may not be the 'key variable determining publishing success' (Hultgren, 2018); such variables are likely to depend on the individual case. Hyland, while acknowledging at certain points the additional linguistic challenges of EAL writers, at the same time argues that there is only one set of challenges, which is shared by both groups. The additional linguistic challenges can be dismissed, according to Hyland, because they are overshadowed by the other challenges attaching to both groups.

How can we explain this fundamental contradiction in Hyland's position? Reading between the lines, perhaps his view is that the linguistic challenges for EAL writers are not part of academic writing but are part of 'general English' and not part of 'academic' or 'discipline-specific' English. They are to be dealt with separately in any pedagogical consideration. This would be a way of explaining the contradiction perhaps, but I would not agree with this position. As stated earlier, I do not think it is possible to compartmentalize the linguistic features that Hyland acknowledges from the academic or discipline-specific features. They need to be considered together.

With regard to the issue of bias, while it is true that there is not systematic empirical evidence for bias, as Hyland correctly claims, there is a certain amount of circumstantial evidence, as I have tried to show in some of my qualitative work (Flowerdew, 2007, 2008, 2009), and, of course, as I have said, by requiring one group (EAL writers) to face up to the challenge of writing in an additional language (English) and allowing another group (L1 writers) not to have to meet this challenge, the whole publication process is biased from the outset.

No doubt, this piece is rather negative. Indeed, I have been highly critical of Hyland's position. His article might have carried more weight if it had been written by an EAL writer rather than an L1 writer. As pointed out by one on-line commenter on Subtirelu's blog piece, it is demeaning for EAL writers to be told by someone writing from the privileged position of an L1 writer that they are misguided if they believe that it is more difficult for them to write for publication than for an L1 writer. And it is not just any L1 writer in question here, but one of the leading scholars in the field of EAP, someone who carries an immense amount of influence. That is not to say that I am encouraging EAL writers to carry a chip on their shoulder. EAL writers, after all, have certain advantages over L1 writers. They are able to communicate to a high level in at least two languages, whereas monolingual Anglophone writers do not have such an advantage. That is why Kramsch (1997) is able to talk about 'the privilege of the Non-Native-Speaker'. Neither do I like the term 'deficit' when discussing challenges for EAL 
writers (Langum \& Sullivan, 2017). To highlight particular challenges is to describe a reality. As Hyland and others (including myself) have noted, published EAL writers are now in the majority and so many (though by no means all) are able to overcome the linguistic challenges they encounter, which is something to celebrate.

Some might think I am behind the times in focusing on this issue of EAL disadvantage. Undoubtedly the field of ERPP has moved on to consider other issues. As Kuteeva and Mauranen (2014, p. 367) state in their introduction to a special edition of Journal of English for Academic Purposes:

The issues related to using English in academic publication surpass the Native versus Non-Native dichotomy, and there are other factors that impact the language choices of multilingual scholars.

As a case in point, for example, in the context of the European periphery countries, the work of Lillis and Curry (2010) downplays the language issue per se and focuses more on the situatedness of writing for publication and in particular the role of language brokers - although it might be argued that there would not be such a need for such brokers if the concerned scholars were not writing in an additional language (English). And it is heartening that - with the growing influence of research on English as a lingua franca and the increase in the numbers of EAL writers joining the editing and reviewing fraternity - emphasis on standard English may be reducing. Indeed, more and more international journals are publishing articles in what may be termed 'Academic English as a lingua franca', not standard English (Rozycki \& Johnson, 2013; Tribble, 2017). Furthermore, as Hyland demonstrates in his table 1, EAL writers are publishing more and more. And as Hynninen and Kuteeva (2017) point out, with EAL writers increasingly in the majority, although there may be a pull to some standard form or forms, such standards, based on criteria of understandability and clarity, are likely be defined by the writers, reviewers, and proofreaders in individual disciplinary discourse communities rather than some externally imposed authority.

Nevertheless, to use a colloquial expression, we do not want to throw the baby out with the bath water. In spite of these positive developments and new foci of research, the linguistic challenges remain. Even if, as just mentioned, lingua franca English is increasingly accepted, there will still be certain standards of intelligibility and clarity that need to be met. It is not a case of 'anything goes'. ${ }^{6}$ That is why universities will still need to provide courses in EAP and in ERPP. We do not want university administrators to use claims such as those of Hyland as an excuse for not offering language support to EAL writers. This article is not negative, therefore, insofar as it seeks to put right what in my view is a significant misunderstanding.

\section{Endnotes}

1 InterLAE, International Conference on Interpersonality in Written Academic Discourse: Perspectives across Languages and Cultures, Jaca, University of Zaragoza, Spain.

${ }^{2}$ The term in Hyland's title is 'myth of injustice' and the 'myth' includes both linguistic disadvantage and reviewer bias. I will discuss both of these issues in this article, although I will put more emphasis on the disadvantage issue.

3 Already two and a half decades ago, Silva (1993, p. 667), in a review of the literature on adult L2 writing concluded that:

The findings from this body of research suggest that, in general terms, adult L2 writing is distinct from and simpler and less effective (in the eyes of $\mathrm{L} 1$ readers) than $\mathrm{L} 1$ writing. Though general process patterns are similar in L1 and L2, it is clear that it is more constrained, more difficult, and less effective. ... In terms of lower level linguistic concerns, L2 writers' stylistically distinct and simpler in structure. Their sentences included more but shorter $\mathrm{T}$ units, fewer but longer clauses, less subordination, less noun modification, and less passivization, evidenced distinct patterns in the use of cohesive devices, conjunctive (more) and lexical (fewer) ties, and exhibited control, variety, and sophistication overall.

${ }^{4}$ Hyland (p. 61) defines register as follows:

The register of academic writing is a specific domain of expertise comprising a sub-set of lexico-grammatical features and rhetorical conventions, which have evolved to perform certain valued functions for those who use them. While its 
regularities and peculiarities vary across disciplines, it is a linguistic code that captures the cultural profile that emerges through the identity investment of academics in creating particular kinds of meanings that insiders will recognize andunderstand.

${ }^{5}$ See also Subtirelu (2016) on this topic.

${ }^{6}$ In my study with Simon Wang (Flowerdew \& Wang, 2016), we examined 15 manuscripts by Chinese researchers which were eventually published in SCI-indexed journals and found that over a hundred corrections were made by the author's editor to each initial draft. This is a far cry from the average of ten non-standard features in the published articles by EAL writers studied by Rozycki and Johnson (2013).

\section{References}

Breeze, R. (2015). Citing outside the community? An investigation of the language of bibliography in top journals. In English as a scientific and research language: Debates and discourses: English in Europe, vol. 2 (pp. 37-58). Berlin: De Gruyter.

Casanave, C. P. (1998). Transitions: The balancing act of bilingual academics. Journal of Second Language Writing, 12, 175203.

Casanave, C. P. (2008). The stigmatizing effect of Goffman's stigma label: A response to John Flowerdew. Journal of English for Academic Purposes, 7, 264-267.

Cowan, J. R. (1974). Lexical \& syntactic research for the design of EFL reading materials. TESOL Quarterly, 8, 388-399.

Duszak, A. (1994). Academic discourse and intellectual styles. Journal of Pragmatics, 21, 291-313.

Englander, K. (2006). Revision of scientific manuscripts by non-native-English-speaking scientists in response to journal editors' language criticism of the language. Journal of Applied Linguistics, 3, 129-161.

Ferguson, G. (2007). The global spread of English, scientific communication and ESP: Questions of equity, access and domain loss. Iberica, 13, 7-38.

Flowerdew, J. (1999). Writing for scholarly publication in English: The case of Hong Kong. Journal of Second Language Writing, 8, 123-145.

Flowerdew, J. (2007). The non-Anglophone scholar on the periphery of scholarly publication. AILA Review, $20,14-27$.

Flowerdew, J. (2008). Scholarly writers who use English as an additional language: What can Goffman's 'Stigma” tell us? Journal of English for Academic Purposes, 7, 77-86.

Flowerdew, J. (2009). Goffman's stigma and EAL writers: The author responds to Casanave. Journal of English for Academic Purposes, 8, 69-72.

Flowerdew, J., \& Li, Y.-Y. (2007). Language re-use among Chinese apprentice scientists writing for publication. Applied Linguistics, 28(3), 440-465.

Flowerdew, J., \& Wang, S. H. (2016). Author's editor revisions to manuscripts published in international journals. Journal of Second Language Writing, 32(2), 39-52.

Habibie, P. (2015). Writing for scholarly publication in Canadian higher education context: A case study. In C. M. Badenhorst, \& C. Guerin (Eds.), Research literacies and writing pedagogies for masters and doctoral writers (pp. 51-67). Leiden: Brill Publishing.

Habibie, P., \& Hyland, K. (2018). Novice writers and scholarly publication: Authors, mentors, gatekeepers. Basingstoke: Palgrave Macmillan.

Halliday, M. A. K. (1989). Spoken and written language. Oxford: Oxford University Press.

Halliday, M. A. K., \& Hasan, R. (1976). Cohesion in English. Harlow: Longman.

Halliday, M. A. K., \& Matthiessen, C. (2004). An introduction to functional grammar (3rd ed.). London: Arnold.

Hewings, A., Lillis, T., \& Vladimirou, D. (2010). Who's citing whose writings? A corpus-based study of citations as interpersonal resource in English medium national and English medium international journals. Journal of English for Academic Purposes, 9, 102-115.

Hultgren, A. K. (2018). The rise of English as the language for academic publication: On equity, disadvantage and 'NonNativeness' as a red herring. Plenary paper presented at 6th PRISEAL conference. University of Iceland: Reykjavik, Iceland.

Hyland, K. (2015). Academic publishing: Issues and challenges in the construction of knowledge. Oxford: Oxford University Press.

Hyland, K. (2016a). Academic publishing and the myth of linguistic injustice. Journal of Second Language Writing, 31, 58-69.

Hyland, K. (2016b). Language myths and publishing mysteries: A response to Politzer-Ahles et al. Journal of Second Language Writing, 34, 9-11.

Hynninen, N., \& Kuteeva, M. (2017). 'Good' and 'acceptable' English in L2 research writing: Ideals and realities in history and computer science. Journal of English for Academic Purposes, 30, 53-65.

Johns, T. F., \& Dudley-Evans, A. (1980). An experiment in team teaching overseas postgraduate students of transportation and plant biology. In Team Teaching in ESP (ELT Documents No. 106) (pp. 6-23). London: The British Council.

Kramsch, C. (1997). The privilege of the non-native-speaker. PMLA, 112(3), 359-369.

Kuteeva, M., \& Mauranen, A. (2014). Writing for publication in multilingual contexts. An introduction to the special issue. Journal of English for Academic Purposes, 13, 1-4. 
Langum, V., \& Sullivan, K. (2017). Writing academic English as a doctoral student in Sweden: Narrative perspectives. Journal of Second Language Writing, 35, 20-25.

Li, J., \& Schmitt, N. (2009). The acquisition of lexical phrases in academic writing: A longitudinal case study. Journal of Second Language Writing, 18, 85-102.

Lillis, T. M., \& Curry, M. J. (2010). Academic writing in a global context. London: Routledge.

Lillis, T. M., \& Curry, M. J. (2015). The politics of English, language and uptake: The case of international academic journal article reviews. AILA Review, 28, 127-150.

Moreno, A. (2012). The communication problems of Spanish researchers to get research articles published in Applied Linguistics English-medium journals: Proposal and analysis. Retrieved from https://buleria.unileon.es/handle/10612/1756

Myers, G. (1990). Writing biology: Texts in the social construction of scientific knowledge. Madison, WI: University of Wisconsin Press.

Paltridge, B. (2016). Writing retreats as writing pedagogy. Writing and Pedagogy, 8(1), 199-213.

Paltridge, B., \& Starfield, S. (2016). Getting published in academic journals: Navigating the publication process. Ann Arbor: University of Michigan Press.

Pérez-Llantada, C. (2012). Scientific discourse and the rhetoric of globalization: The impact of culture and language. London/ New York: Continuum.

Pérez-Llantada, C. (2015). Genres in the forefront, languages in the background: The scope of genre analysis in language-related scenarios. Journal of English for Academic Purposes, 19, 10-11.

Politzer-Ahles, S., Holliday, J. J., Girolamod, T., Spychalskae, M., \& Harper Berkson, K. (2016). Is linguistic injustice a myth? A response to Hyland (2016). Journal of Second Language Writing, 34, 3-8.

Robinson, P. (1980). English for specific purposes, Oxford: Pergamon.

Rozycki, W., \& Johnson, N. H. (2013). Non-canonical grammar in Best Paper award winners in engineering. English for Specific Purposes, 20, 89-100.

Shi, L. (2003). Writing in two cultures: Chinese professors return from the West. The Canadian Modern Language Review, 59, 369-391.

Silva, T. (1993). Toward an understanding of the distinct nature of L2 writing: The ESL research and its implications. TESOL Quarterly, 27(4), 657-677.

Subtirelu, N. (2016). Language privilege: What it is and why it matters. [Web log post]. Retrieved from https://linguisticpulse. com/2013/06/26/language-privilege-what-it-is-and-why-it-matters/

Swales, J. M. (2004). Research genres. Cambridge: Cambridge University Press.

Tribble, C. (2017). ELFA vs genre: A new paradigm war in EAP writing instruction? Journal of English for Academic Purposes, 25, 30-44.

Trimble, L. (1985). English for Science and Technology: A Discourse Approach, Cambridge: Cambridge University Press.

Williams, I. A. (1999). Results sections of medical research articles: Analysis of rhetorical categories for pedagogical purposes. English for Specific Purposes, 18, 347-366.

John Flowerdew is a Visiting Chair at the University of Lancaster and a Visiting Research Fellow at Birkbeck College, University of London. He has published well over a hundred books, journal articles, and book chapters. His books on English for academic purposes/academic discourse include Academic listening: Research perspectives (Cambridge), Research perspectives in English for Academic Purposes (with M. Peacock) (Cambridge), Academic discourse (Longman), Signalling nouns in discourse: A corpus-based discourse approach (with R. W. Forest) (Cambridge), and Discipline specific writing: Theory into practice (with T. Costley) (Routledge). One of his main interests over the years is writing for publication by EAL scholars. He is also interested in critical discourse studies and has recently published The Routledge handbook of critical discourse studies (with J. Richardson).

Cite this article: Flowerdew, J. (2019). The linguistic disadvantage of scholars who write in English as an additional language: Myth or reality. Language Teaching, 52(2), 249-260. https://doi.org/10.1017/S0261444819000041. 